\title{
MAPAS SOCIAIS E A CARTOGRAFIA DO PASSADO: MEMÓRIAS TOPOGRÁFICAS DOS TUXÁ DE RODELAS-BA
}

\author{
SOCIAL CHARTS AND CARTOGRAPHY \\ OF THE PAST: TUXA' PEOPLE'S \\ TOPOGRAPHIC MEMORIES IN \\ RODELAS-BA
}

\section{Leandro Durazzo}

leandrodurazzo@gmail.com

Doutorando em Antropologia Social, PPGAS/UFRN ${ }^{l}$

\section{RESUMO}

A partir do histórico recente dos Tuxá de Rodelas, povo indígena habitante da margem baiana do rio São Francisco, refletiremos acerca dos impactos socioterritoriais acarretados por grandes empreendimentos como barragens, hidrelétricas e consequentes deslocamentos compulsórios, mas também dos reflexos cartográficos que tais deslocamentos produzem na autorrepresentação dos sujeitos afetados. Para isso, analisamos brevemente o cenário de remoção dos Tuxá em finais dos anos de 1980, quando da construção da hidrelétrica de Itaparica e do subsequente enchimento de seu lago. A hidrelétrica inundou áreas próximas e encobriu totalmente a terra indígena tuxá existente até aquele momento, a Ilha da Viúva, ilha sanfranciscana mantida pelo povo como local de produção agropecuária para subsistência e também como espaço preferencial de práticas rituais. Em seguida, tratamos de alguns usos acadêmicos que pesquisadores tuxá têm realizado de materiais cartográficos antigos, como os mapas históricos da região produzidos sob ordens imperiais, e aventamos a hipótese de que tais usos tuxá de antigos materiais técnicos têm possibilitado novas modalidades de agência indígena no seio do universo acadêmico, no qual continuamente ampliam sua presença. Por fim, buscamos evidenciar como a autorrepresentação cartográfica dos Tuxá atuais faz coexistirem, simultaneamente, a paisagem contemporânea da região em que vivem e as memórias topográficas que, passadas décadas, permanecem centrais para as narrativas e descrições sobre o rio São Francisco antes do represamento.

Palavras-chave: Etnologia Indígena do Nordeste. Cartografia Social; Memória e Imaginário.

\begin{abstract}
This paper considers socioterritorial impacts caused by enterprises such as dams and its following displacements upon Tuxá indigenous people of Rodelas, Bahia. We also take into consideration some developments on Tuxá's cartographic representations, considering them as a people impelled out of their lands by a dam built during 1970s and 1980s. Part of the lands submerged at that time included Widow's Island, a river island owned
\end{abstract}


by Tuxá people and a place of both rural working and ritual practices. Afterwards we will consider a few academic uses Tuxá researchers are doing nowadays, resorting to ancient imperial charts to bold their present indigenous thoughts and politics of ethnicity. Lastly, we will follow processes by which Tuxá people make coexist both present regional landscape and their topographic memories of the place, still critical to understand their narrated stories and descriptions of São Francisco river before its damming.

Keywords: Ethnology of Northeastern Brazil. Social Cartography. Memory and Imaginary.

\section{INTRODUÇÃO}

Os atuais Tuxá ${ }^{2}$ são, historicamente, considerados descendentes dos antigos índios rodeleiros, habitantes autóctones da região do Submédio São Francisco que figuram na literatura e na memória do povo como relacionados ao Capitão Francisco Rodelas, de quem deriva seu nome (SAMPAIO-SILVA, 1997, p. 31; SALOMÃO, 2006, p. 61). Este teria acompanhado as expedições do também indígena Filipe Camarão no esforço português para expulsar os holandeses de sua então colônia, donde se origina sua patente de capitão. Daí a provável coincidência etno- e toponímica que aproxima rodeleiros, Francisco Rodelas e o próprio "Sertão de Rodellas" (GALINDO, 2004, p. 75), conhecido por tal nome desde o período colonial.

Sabe-se que as primeiras identificações de um grupo denominado Tuxá datam do século XVIII. Como lemos em Hohenthal, "Estes índios foram encontrados com os Periá, em 1759, no Rio São Francisco, na região imediatamente oposta à confluência do Rio Pajeú, o que os coloca nas redondezas de Rodelas" (HOHENTHAL, apud CABRAL NASSER, 1975, p. 12). A área situada defronte ao rio mencionado, conhecida por Barra do Pajeú, é imediação de um dos territórios mais ancestrais para o povo, denominado Dzorobabé (na língua Dzubukuá, reputada língua ancestral do povo Tuxá; a região também recebe o nome de Surubabel ou Sorobabé, em diferentes registros vernaculares), hoje em intenso processo de autodemarcação pelos Tuxá, tópico ao qual retornaremos.

Ocupando a região de Rodelas desde há séculos, e tendo convivido com aldeamentos missionários, outros grupos indígenas e uma série de processos históricos bastante dinâmicos pela natureza de fronteira de expansão colonial do sertão, os Tuxá costumam ser considerados grandes conhecedores da região. Eram, quando à época do rio corrente, exímios navegadores, canoeiros e transportadores de passageiros e cargas pelas águas do São Francisco, desde Paulo Afonso-BA até Pirapora-MG. Segundo a tradição narrada por muitos índios e regionais, também tinham a posse de mais de trinta ilhas fluviais naquele trecho do rio, mas na metade do século passado já viam suas posses territoriais reduzidas a apenas uma, a Ilha da Viúva (SALOMÃO, 2006, p. 77-78). Além desta, habitavam uma aldeia em terra firme, contígua à cidade de Rodelas, de onde partiam para trabalhar na terra e cuidar dos animais na ilha.

Por ser último reduto totalmente indígena ao alcance dos Tuxá de Rodelas, a Ilha da Viúva era também o local preferencial para a prática de rituais religiosos. Ou, melhor dizendo, para a prática de rituais e obrigações, segmentos e trabalhos da ciência do índio, isto é, o complexo sociocosmológico e ritual que compõe as vivências xamânicas entre os Tuxá. Essa ciência é categoria nativa bastante difundida entre povos indígenas da região, normalmente estabelecendo em seu bojo a existência de práticas como o toré (cf. GRÜNEWALD, 2005), ritual lúdico e coreográfico-musical, cuja assistência de não-indígenas é permitida, mas também práticas como o particular ou oculto, restritas a indígenas que trabalham na ciência. $\mathrm{O}$ antropólogo tuxá Felipe Cruz assim expõe o tópico: 
O Particular é uma prática ritual Tuxá bastante restrita e importante para o meu povo. É no particular que os índios adultos se reúnem para 'trabalhar no segmento' que diz respeito a cumprir com a nossa 'obrigação' de se manter conectados com nossos ancestrais e com as entidades chamadas 'encantados' que guiam a nossa experiência do presente e do futuro. O particular pode durar uma noite inteira, e envolve os participantes em uma série de prescrições que devem ser observadas pelos participantes no período que antecede o seu acontecimento. (CRUZ, 2017, p. 56, n. 17).

Pelo exposto, compreende-se facilmente o caráter fulcral da Ilha da Viúva para os Tuxá que a percorriam e nela trabalhavam até a década de 1980, data da mudança brusca em seu modo de vida e no sentimento de pertença territorial.

Entre os anos de 1970 e o derradeiro 1988, quando os Tuxá foram removidos de suas terras - tanto da Ilha da Viúva quanto da aldeia contígua a Rodelas - a Companhia Hidrelétrica do São Francisco (CHESF), subsidiária da estatal Centrais Elétricas Brasileiras S.A. (Eletrobras), implementou a jusante de Rodelas um projeto de represamento que resultaria na hidrelétrica de Itaparica, atualmente denominada Usina Hidrelétrica Luiz Gonzaga. Sob a perspectiva de grande impacto social, três dos primeiros trabalhos antropológicos com os Tuxá foram realizados, ainda nos anos de 1970: as dissertações de Nássaro Nasser (1975) e Elizabeth Cabral Nasser (1975), e o trabalho inicialmente técnico de Orlando Sampaio-Silva em 1975 e 1976, a pedido da CHESF, que depois resultou em dissertação e livro (1997).

Todos os três enfatizavam, já nos primeiros anos de estudos para implementação do projeto, que o impacto sobre a população indígena acarretaria mudanças indeléveis na relação tuxá com o ambiente. Sampaio-Silva apontaria o caráter desenvolvimentista da ação estatal, em um cenário de regime civil-militar, tecendo críticas à lógica subjacente a tais empreendimentos e pontuando argutamente os resultados sociais previstos. Dizia haver um:

Pressuposto de que há uma relação direta ou um nexo de causalidade entre a produção de energia elétrica e o progresso, o desenvolvimento capitalista e, consequentemente, a solução dos problemas sociais. Este pressuposto está comprovadamente equivocado, uma vez que, após tantos anos de construções e funcionamento de hidrelétricas no Nordeste do país, a grande massa da população permanece no imobilismo social, estagnada na pobreza. [Os] custos sociais da execução destes grandes projetos de engenharia são extremamente altos, não só no que se refere ao custo financeiro das obras em si mesmas, como também e principalmente pelas repercussões sobre as populações não indígenas e indígenas que são diretamente (e indiretamente) atingidas pelas inundações. (SAMPAIO-SILVA, 1997, p. 176).

O trabalho de Ricardo Salomão, cujo campo se deu no início dos anos 2000, realizou um levantamento bastante atento aos desdobramentos jurídicos e sociais vividos pelos Tuxá após a mudança para a nova cidade. O antropólogo detalha os sucessivos acordos tentados pela CHESF para se desincumbir das contrapartidas previstas com relação aos Tuxá, quais sejam, uma sequência de propostas de indenizações e termos de ajustamento de conduta que visaram a desobrigar a empresa de assegurar a demarcação de uma terra indígena tuxá. (SALOMÃO, 2006, p. 155).

Passados trinta anos de enchimento do lago para início do funcionamento da hidrelétrica, os Tuxá de Rodelas ainda não possuem uma terra indígena regularizada nos termos iniciais previstos no projeto. A CHESF, ao 
longo das décadas, não concluiu as contrapartidas referentes ao povo indígena em questão, elaborando uma série de artifícios para postergar o acordo inicial. Como afirma Felipe Cruz:

O desdobramento das negociações do reassentamento Tuxá chegou a um desfecho muito diferente do que havia sido acordado nos convênios que antecederam a inundação. Os Termos de Ajustamento de Conduta celebrados entre os Tuxá, a CHESF e o [Ministério Público Federa] MPF se tornaram peças legais que atuam como supostas 'mediações' exercidas pelas instâncias deliberativas, que sempre estão 'pré-dispostas' a interpelar por uma 'conciliação' entre interesses empresarias e direitos humanos [...], mas que atuam de fato como formas de flexibilizar direitos fundamentais estabelecidos na legislação brasileira. (CRUZ, 2017, p. 106).

Com o passar do tempo e a inserção cada vez mais significativa de estudantes tuxá no ensino superior, temos visto trabalhos acadêmicos atentando-se para tais estratégias de desobrigação por parte da empresa: em 2017, Felipe Cruz elabora sua dissertação em Antropologia Social pela UnB abordando "Os índios Tuxá de Rodelas e a barragem de Itaparica: memórias do desterro, memórias da resistência" (CRUZ, 2017); no mesmo ano, o advogado e liderança tuxá Dinamam Jesus Vieira defende dissertação sobre "Os índios Tuxá na rota do desenvolvimento: violações de direito" (JESUS VIEIRA, 2017); e um ano antes temos a monografia de Élton Fábio Santos Vieira, em Engenharia Civil, abordando "impactos geoambientais e culturais decorrentes da implementação da barragem de Itaparica". (SANTOS VIEIRA, 2016).

Muitos outros trabalhos de conclusão de curso já foram ou estão sendo elaborados por pesquisadores tuxá. A menção aos três acima, entretanto, torna-se significativa por algumas razões. Primeiramente, as dissertações de Felipe Cruz e Dinamam Jesus Vieira adquirem relevância acadêmica e institucional singular por serem trabalhos pós-graduados, diretamente vinculados à discussão dos impactos sociais pós-barragem sob uma perspectiva antropológica.

Já o trabalho de Santos Vieira faz uso de recursos técnicos e cartográficos até então pouco observados na bibliografia sobre os Tuxá, quais sejam, os mapas oitocentistas do engenheiro Henrique Halfeld (1860), elaborados a pedido do então imperador Dom Pedro II. Manejado como material de análise por um engenheiro indígena, no claro intuito de construir sua argumentação acadêmica, científica e eminentemente política com relação aos impactos sociais ocasionados pela barragem, os mapas técnicos de Halfeld adquirem características de validação de uma causa muito distinta daquela pela qual foram criados.

Se no século XIX Halfeld elabora seu "Atlas e relatório concernente a exploração do rio São Francisco desde a cachoeira de Pirapóra até ao Oceano Atlântico, levantado por ordem do governo de S.M.I. o Senhor Dom Pedro II" (HALFELD, 1860, grafia original), no século XXI teremos o trabalho de Santos Vieira dedicado:

a todos os povos indígenas que foram atingidos por barragens, em especial ao Povo Tuxá, que até hoje luta pelos seus direitos, e valorização de sua identidade étnico-cultural, mesmo vendo parte de sua história e de seus sonhos [...] inundadas pelo progresso. (SANTOS VIEIRA, 2016, s/p).

A mudança de ênfase pragmática, senão utilitária, entre um projeto e outro é notável. A ela nos dedicaremos no tópico que segue, buscando elencar elementos que contrastem diferentes usos cartográficos e de representação socioespacial numa mesma região do Submédio São Francisco. 


\section{NOVOS USOS CARTOGRÁFICOS}

Como o título do atlas de Halfeld já deixa entrever, parte das motivações que oportunizaram o projeto diz respeito à "exploração do rio São Francisco". Assim nos explica o próprio Halfeld as razões de tal levantamento cartográfico:

Para dar conhecimento do estado em que se acha a navegação sobre as aguas do rio de S. Francisco e seus confluentes; das circumstancias que a favorecem; dos obstaculos que a difficultão ou totalmente impedem; a designação dos projectos e meios que julgo dever-se applicar ou que se offerecem para effectuar-se o melhoramento do mesmo rio [...] (HALFELD, 1860, p. 2, grafia original).

Para além da exploração do rio, portanto, o projeto cartográfico de Halfeld, a mando imperial, visava também a indicar "projectos e meios" pertinentes, sob sua ótica, para o "melhoramento do mesmo rio". Pouco acima pudemos constatar, embora em momento histórico distinto e concernente a outro modo de exploração fluvial, que os "custos sociais da execução destes grandes projetos de engenharia são extremamente altos" (SAMPAIO-SILVA, 1997, p. 176). Em finais do século XIX, senão voltada à geração de energia e ao desenvolvimento capitalista, a exploração técnica do rio São Francisco também tendia a diminuir - ou mesmo invisibilizar - populações tradicionais de suas margens, como os Tuxá de Rodelas.

Halfeld descreverá, à légua 297 de seu atlas, a "Missão de S. João Baptista de Rodellas", com uma povoação de:

33 casas de mui inferior construcção, e cobertas de palha de coqueiro de Carnaúba, com cerca de 140 habitantes que são Indios pela maior parte mestiçados com europeos, e que vivem miseravelmente do plantio de mandioca, arroz, abobaras, feijão, algodão, d'alguma pesca e tratão em ponto insignificante da criação de gado, e ajustão-se para o serviço das embarcações. (HALFELD, 1860, p. 41, grafia original).

Não será despropositado recordar João Pacheco de Oliveira quando este discute uma "etnologia dos "índios misturados" (PACHECO DE OLIVEIRA, 1998). O mesmo desinteresse pelos povos indígenas do Nordeste, seguido de sua invisibilização histórica até meados do século XX, quando estes passam a se organizar mais fortemente em movimentos sociais e políticos, está refletido na descrição da Missão de Rodellas. "Indios pela maior parte mestiçados", diz o engenheiro imperial, e mestiços que laboram "alguma pesca" e "em ponto insignificante da criação", como nos afirma o texto. Não parece de pouca monta, portanto, a eleição dos descritores acima: "alguma" e "insignificante", em contexto de "exploração do rio S. Francisco", certamente compuseram o discurso técnico e oficial que melhor configurava os interesses econômicos do Império do Brasil.

O discurso do progresso e do desenvolvimento surge também no trabalho do engenheiro tuxá. A tônica, entretanto, diverge consideravelmente daquela desenvolvimentista, técnica e simplesmente oficial. Falando sobre a barragem de Itaparica, o autor pondera:

O enchimento de um grande reservatório inutiliza grandes áreas agricultáveis com grande potencial de produção, além de destruir sítios arqueológicos; demanda, ainda, a retirada de povos tradicionais de áreas tidas como sagradas por esses indivíduos, o que ocasiona conflitos entre os seus membros e a empresa responsável pela construção da barragem, 
bem como, na maioria das vezes, negociações intermináveis com o Estado. (SANTOS VIEIRA, 2016, p. 26).

Pela conjuntura tuxá pós-barragem, diversas considerações territoriais são levantadas ao aventarem possibilidades de reparação das perdas de território e modos de vida, como mencionado. Os trabalhos de Cruz (2017) e Jesus Vieira (2017), já citados, lidam com o histórico de alterações nos acordos de restituição territorial que a CHESF deveria cumprir. A pesquisa de Santos Vieira (2016), agora em tela, também considera algumas dessas sequências de "ajustamentos" por parte da estatal. Publicada em 2016, a monografia discute, para além do impacto da barragem em 1980, movimentações recentes que visavam a sanar a dívida histórica com os Tuxá.

Entre elas, o engenheiro tuxá destaca o decreto presidencial $n^{\circ}$ 1303/2014, renovação de um decreto já caducado em 2011, inicialmente assinado pelo ex-presidente Luiz Inácio Lula da Silva. O primeiro, decretado em 2009, previa a desapropriação de um imóvel rural para fins de "interesse social" e reassentamento da comunidade indígena Tuxá de Rodelas (JESUS VIEIRA, 2017, p. 16). O decreto de 2014, assinado pela ex-presidenta Dilma Rousseff e suspenso em 2015 pelo ministro do Supremo Tribunal Federal, Gilmar Mendes, previa processo semelhante de desapropriação de imóvel rural para fins de assentamento e interesse social. ${ }^{3}$

É no estudo desses processos recentes de reassentamento, ainda inconclusos, que o engenheiro tuxá recorre aos mapas de Halfeld para sustentar sua reflexão acadêmica, ao mesmo tempo que corrobora a memória de pertencimento territorial que inúmeras vezes ouvimos dos mais velhos, como o pajé tuxá Armando Apako. O pajé costuma refletir sobre o território dos antigos rodeleiros, informando limites topográficos que abrangem grande parte da margem baiana do Submédio São Francisco. Santos Vieira fará o mesmo, ao lançar mão de Halfeld para pensar a sobreposição histórica da Missão de Rodellas com as possibilidades que àquele momento indicavam um reassentamento por decreto presidencial. (SANTOS VIEIRA; SANTOS; CARELLI, 2015).

Já em sua monografia, o Tuxá elege o seguinte trecho da carta $\mathrm{n}^{\mathrm{o}} 25$ de Halfeld para representar o "mapa geral da área ocupada" pelos Tuxá, e que a eles pertencia (SANTOS VIEIRA, 2016, p. 42):

Figura 1 - Missão de Rodellas e imediações, detalhe do mapa $\mathrm{n}^{\circ} 25$

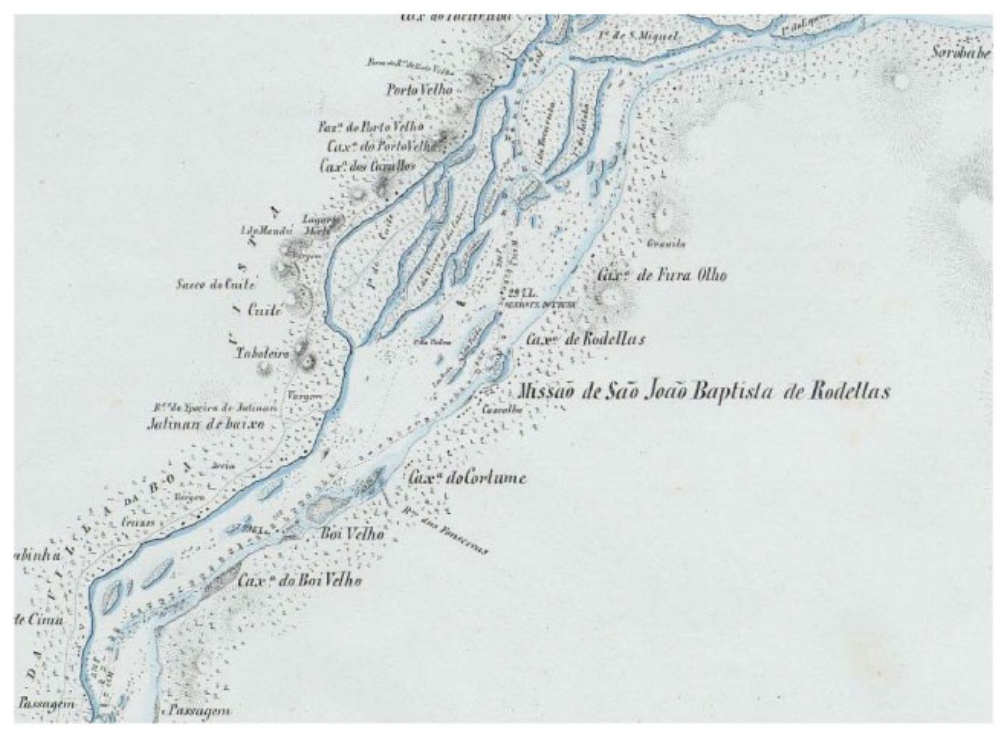

Fonte: HALFELD, 1860, s/p. 
Na carta, podemos observar uma abrangência geográfica considerável, que em muito concorda com a concepção regional de que todo o sertão de Rodelas fosse de ocupação dos rodeleiros, dentre outros povos de etnônimos mais definidos como os próprios Tuxá (Tuša), Periá e Procá, na margem oposta do rio (NIMUENDAJU, 2017). Ainda, nota-se no recorte estabelecido pelo engenheiro tuxá um ponto que expande e ao mesmo tempo antecede, cronologicamente, a ocupação de Rodelas. Este, no limite superior direito do mapa, é o território tradicional de Sorobabé, ou Dzorobabé.

Contam os relatos históricos e antropológicos que, antes de seguirem para o que hoje é Rodelas, os indígenas seguidores de Francisco Rodelas viviam em uma ilha fluvial chamada Sorobabé, como na carta. Por ocasião de uma enchente, provavelmente do Pajeú, em algum momento do século XVIII o grupo abandonou a ilha inundada e se estabeleceu na margem baiana. Tal território é considerado como tradicionalmente dos atuais Tuxá, e uma série de processos de escavação arqueológica corroboram tal compreensão (SANTOS, 2008).

Os Tuxá encontram-se, desde meados de 2017, em processo de retomada da área de Dzorobabé. Essa autodemarcação territorial, motivada sobretudo pela lentidão observada com relação aos processos oficiais que deveriam ser efetivados pela União e pela Funai, atualmente restabelece o território dos antigos rodeleiros e o reaviva, no sentido de estabelecer em sua área uma nova aldeia tuxá. Tal processo, decerto influenciado pela experiência de trinta anos à espera da CHESF, não obstante se diferencia dela, já que autodemarca o território considerado tradicional não por uma dívida devida a grandes empreendimentos, mas ao reconhecimento de uma ancestralidade que o grupo étnico reforça e amplifica.

Quanto ao trabalho de engenharia tuxá que aqui vimos analisando, vale retomarmos a reflexão do autor. Para além da utilização do mapa cartográfico imperial na monografia citada, o pesquisador tuxá também procede a uma "reconstituição histórica e geopolítica do povo Tuxá" (em coautoria com colegas de sua instituição de origem, a Universidade Estadual de Feira de Santana - UEFS). (SANTOS VIEIRA; SANTOS; CARELLI, 2015). Esta reconstituição se dá ainda no processo de confecção de sua monografia, pelo que possui a perspectiva de efetivação do decreto presidencial de 2014, irrealizado até o momento.

O recorte geográfico e as técnicas cartográficas utilizadas, entretanto, mostram-se bastante compatíveis com a atualização indígena de um procedimento que em 1860 víamos como de interesse explicitamente não-indígena, porquanto estatal. Utilizando tecnologia aeroespacial, o engenheiro tuxá, junto a duas pesquisadoras não-indígenas, apresentam cartografias prospectivas a fim de reconstituir, "a partir de imagens de satélite, a desterritorização do povo Tuxá, a partir da implantação da Barragem de Itaparica" (SANTOS VIEIRA; SANTOS; CARELLI, 2015, p. 7135), bem como:

“. Mensurar o antigo território Tuxá, constituído pelas ilhas fluviais do Rio São Francisco de Bélem do São Francisco ao Rio Pajeú;

- Identificar o novo território determinado pelo decreto 13/03/2014 e comparar a distribuição de terras

- Avaliar a possibilidade de, nesse novo território, recriar os diferentes aspectos sociais, políticos e econômicos do povo Tuxá (SANTOS VIEIRA; SANTOS; CARELLI, 2015, p. 7136). 
Vejamos, pois, as imagens elaboradas pelos pesquisadores e apresentadas no âmbito do XVII Simpósio Brasileiro de Sensoriamento Remoto - SBSR, ocorrido em João Pessoa-PB no ano de 2015. No primeiro par de mapas, observamos registros do mesmo trecho do rio onde se situa Rodelas e Dzorobabé. À esquerda, a região em 1978, dez anos antes do enchimento do lago; à direita, 2008, vinte anos após o impacto da inundação:

Figuras $2 \mathrm{a}$ e $2 \mathrm{~b}$ - Limite norte do município de Rodelas-BA; trecho compreendido entre as coordenadas $8^{\circ} 47^{\prime} 54.9^{\prime \prime} \mathrm{S} 38^{\circ} 52^{\prime} 48.6^{\prime \prime} \mathrm{W}$ e $8^{\circ} 53^{\prime} 56.0^{\prime \prime} \mathrm{S} 38^{\circ} 42^{\prime} 00.4^{\prime \prime} \mathrm{W}$, esta correspondendo à barra do rio Pajeú
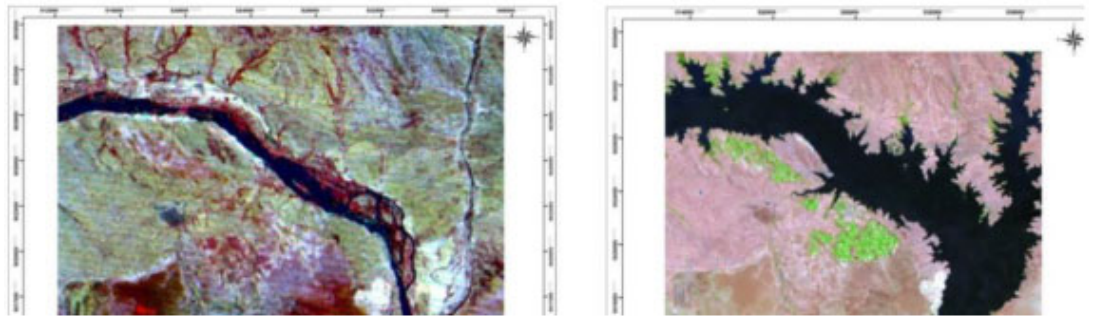

Fonte: SANTOS VIEIRA, SANTOS, CARELLI, 2015, p. 7137.

Dispondo de imagens com uma abrangência geográfica maior, os autores indicam, ainda, as ilhas que historicamente pertenceram aos índios e que foram submersas pelo empreendimento. Note-se que as terras insulares inundadas, ainda que não se encontrassem mais na posse oficial dos Tuxá, somavam uma área em torno de 1.600 ha (SANTOS VIEIRA; SANTOS; CARELLI, 2015, p. 7137).

Figuras 3a e 3b-Limite norte do município de Rodelas-BA; trecho compreendido entre as coordenadas $8^{\circ} 47^{\prime} 60.0^{\prime} \mathrm{S} 38^{\circ} 55^{\prime} 27.8^{\prime \prime} \mathrm{W}$ e $8^{\circ} 55^{\prime} 49.5^{\prime}$ 'S $38^{\circ} 28^{\prime} 05.5^{\prime \prime} \mathrm{W}$, esta correspondendo à margem pernambucana no município de Petrolândia
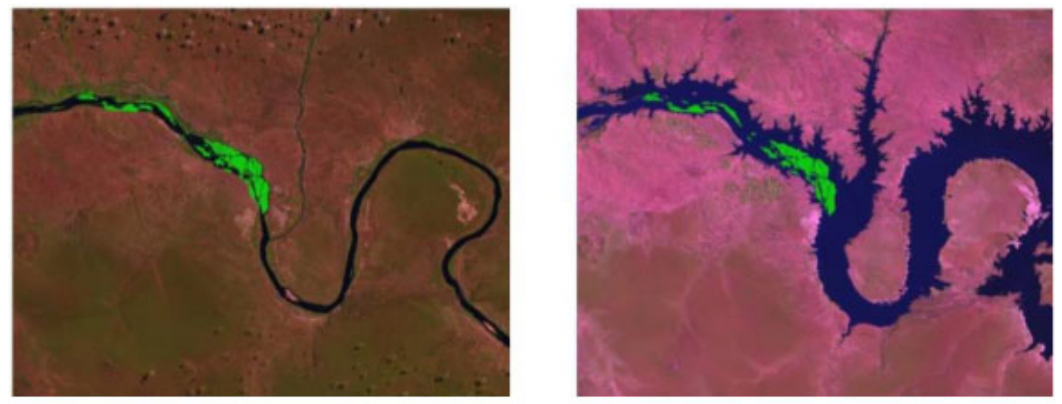

Fonte: SANTOS VIEIRA, SANTOS, CARELLI, 2015, p. 7137.

De especial interesse, entretanto, será a cartografia perspectiva que os pesquisadores realizarão, ainda sob a expectativa de implementação do reassentamento por interesse social, como estabelecido no decreto presidencial de 2014. Analisando a área de 4.390 ha prevista na determinação presidencial, tem-se uma dimensão do aumento territorial que os Tuxá teriam a disposição, após quase trinta anos assentados em uma área diminuta contígua à cidade (na figura $4 \mathrm{~b}$, em amarelo): 
Figuras $4 \mathrm{a}$ e $4 \mathrm{~b}$ - Limite norte do município de Rodelas-BA; trecho compreendido entre as coordenadas $8^{\circ} 47^{\prime} 60.0^{\prime \prime} \mathrm{S} 38^{\circ} 55^{\prime} 27.8^{\prime \prime} \mathrm{W}$ e $8^{\circ} 55^{\prime} 49.5^{\prime} \mathrm{S} 38^{\circ} 28^{\prime} 05.5^{\prime \prime} \mathrm{W}$, esta correspondendo à margem pernambucana no município de Petrolândia
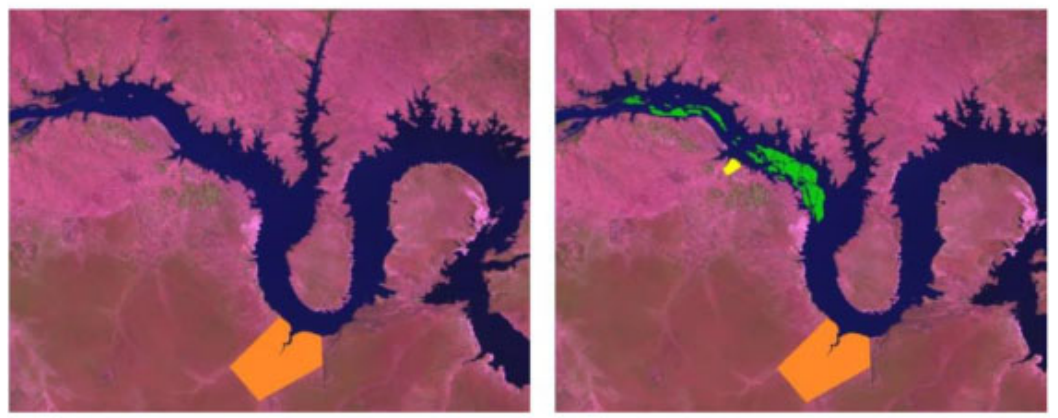

Fonte: SANTOS VIEIRA; SANTOS, CARELLI, 2015, p. 7138.

A imagem $4 \mathrm{a}$, à esquerda, indica a delimitação do imóvel rural previsto para ser destinado aos Tuxá. $\mathrm{Na} 4 \mathrm{~b}$, à direita, temos uma composição cartográfica de sensível relevância para nossa reflexão presente. Nele, vemos a sobreposição das três "reservas históricas dos Tuxás, desde sua remoção em 1986, pelo acionamento da Barragem de Itaparica: em verde, a mais antiga, em amarelo, o atual 'acampamento', em laranja a Reserva a ser implantada" (SANTOS VIEIRA; SANTO; CARELLI, 2015, p. 7138).

Os usos técnicos do conhecimento cartográfico, como vemos, permitem a agentes indígenas uma interlocução não apenas acadêmica, mas efetivamente política com relação à apresentação de suas demandas e necessidades. Além disso, a elaboração de cartas como as vistas acima, por sensoriamento remoto, e sua veiculação em fóruns técnicos interétnicos, como o simpósio no qual o trabalho de 2015 é apresentado, servem como novos campos de afirmação étnica.

Não obstante, o avanço tecnológico e a ampliação de repertórios intelectuais não-indígenas não fazem desaparecer determinadas relações tradicionais com o espaço habitado. A última imagem, sobrepondo três territórios indígenas cronologicamente separados - e projetando uma perspectiva de futuro ainda inalcançada - faz convergirem distintos modos de representar o espaço e $o$ pertencimento territorial. A memória da Ilha da Viúva, por exemplo, revela-se na manutenção da área verde no mapa, bem como no discurso cotidiano dos Tuxá de Rodelas: tendo sido deslocados do antigo território há três décadas, os atuais anciãos do povo eram, à época da mudança, adultos de quarenta ou cinquenta anos. Haviam passado uma vida inteira, portanto, de trabalho e andanças pelas ilhas e pelo curso do rio. Muitos dos atuais adultos tuxá de Rodelas também recordam da vida na ilha, onde trabalhavam com seus pais e parentes.

Destarte, a sobreposição de territórios na última imagem apresentada pelo grupo do engenheiro tuxá, mais do que simples recurso didático, traz-nos à atenção um elemento crucial para a compreensão da memória tuxá e de certas dinâmicas presentes nos últimos trinta anos de vida deste povo. É a este complexo de autorrepresentações cartográficas que passaremos agora.

\section{NOVAS CARTOGRAFIAS SOCIAIS}

Em 2008, sob a rubrica do projeto Nova Cartografia Social dos Povos e Comunidades Tradicionais do Brasil ${ }^{4}$, em seu recorte junto a povos indígenas pela Bacia do São Francisco, os Tuxá de Rodelas desenvolveram um mapa social representando sua realidade à época. Considerando o ano de elaboração 
da oficina, passavam-se duas décadas desde o enchimento do lago, e o impacto social do empreendimento da CHESF permanecia central para o entendimento da vida tuxá daquele período - como permanece, podemos afirmar, também para a compreensão atual do "ser Tuxá", como por vezes designam seu entendimento étnico e existencial face às situações históricas pelas quais passam, dentre elas o deslocamento de 1988.

Organizada por Juracy Marques dos Santos, a atividade resultou em fascículo impresso e disponível digitalmente, cuja página central, dupla, apresenta o mapa elaborado pela comunidade (SANTOS et al., 2010, p. 6-7). É importante ressaltar que a elaboração de um mapa étnico, numa Nova Cartografia Social, constitui-se a partir de um esforço colaborativo e comunitário. Cerca de trinta indígenas participaram da atividade proposta pelo projeto, de variadas faixas etárias, e puderam expressar graficamente o que rapidamente constatamos ao ouvir as falas dos Tuxá contemporâneos: a CHESF, a barragem e a mudança surgem como um - metafórico e literal - divisor de águas na história do povo.

A representação imagética desse impacto, portanto, enfatiza seu caráter incontornável e terrífico, como observamos na legenda e na escolha de sua iconicidade:

Figura 5 - Mapa situacional do povo Tuxá de Rodelas em 2008

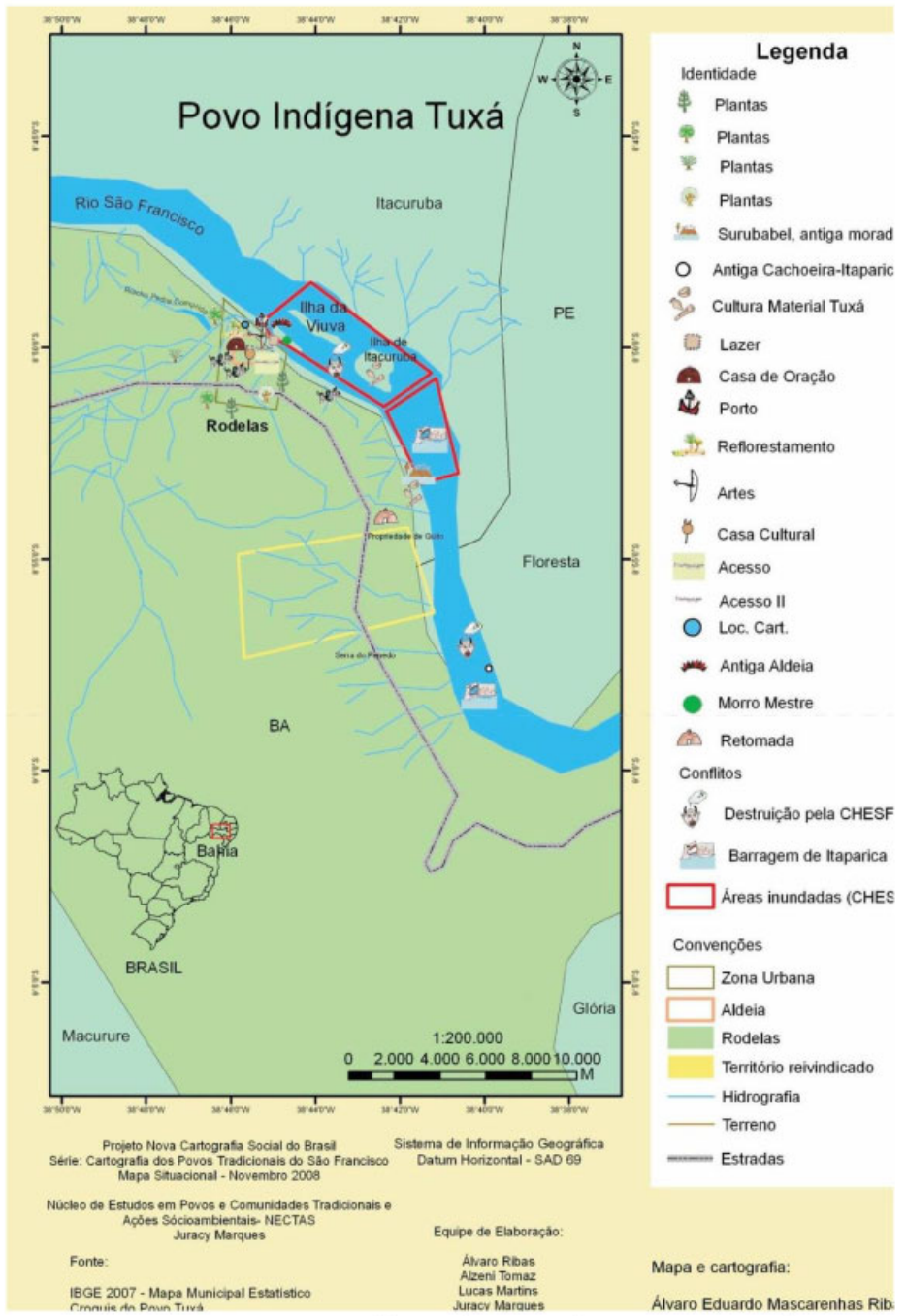

Fonte: SANTOS et al., 2010, p. 6-7. 
Detenhamos nossa atenção a alguns aspectos deste cartograma. Confeccionado em 2008, apresenta a mesma sobreposição espaço-temporal da última imagem de Santos Vieira, Santos e Carelli (2015, p. 7138; cf. figura 4b, acima): na figura 5, a Ilha da Viúva, a nova Rodelas com sua nova aldeia e a barragem de Itaparica encontram-se num mesmo plano cartográfico, sem indicações cronológicas quanto às sucessivas fases que fizeram a ilha desaparecer e a nova aldeia ser construída.

Há outras sobreposições temporais, se considerarmos a legenda da "Cultura Material Tuxá" junto às ilhas de Itacuruba e Surubabel. Como sabemos pelo trabalho de Santos (2008), quando do enchimento do lago houve certo esforço arqueológico por parte da CHESF para preservar alguns artefatos encontrados na região. Os Tuxá, atualmente, aguardam a repatriação de tais objetos, tendo movido pedido formal para que a Universidade do Estado da Bahia (UNEB) acompanhasse tal processo (SANTOS, 2008, p. 15).

Havia também um processo de retomada indicado já antes de 2010, bem como um perímetro amarelo indicando um "território reivindicado" que se delineou no decreto de 2009 , de certo modo próximo ao imóvel rural que viria a ser determinado pelo decreto de 2014 (figura 4a). Na figura 5, vemos que o território reivindicado encontra um de seus limites na Serra do Penedo, referência topográfica a qual os decretos de 2009 e 2014 também se referem. Ambos os decretos, entretanto, definirão seus marcos em coordenadas que delimitam uma área poucos quilômetros distante do território reivindicado na cartografia social, a jusante do rio. Se acompanharmos o contorno roxo da estrada na figura 5 , veremos que seu ponto mais ao sul corresponde ao que se denomina, na região, Baixa do Penedo (CRUZ, 2017, p. 63; JESUS VIEIRA, 2017, p. 17) ou Volta do Penedo, correspondente ao território que seria demarcado em favor dos Tuxá pelo decreto de 2014, e que Santos Vieira, Santos e Carelli (2015, p. 7138) representam precisamente ao delimitarem as coordenadas em laranja, nas figuras $4 \mathrm{a}$ e $4 \mathrm{~b}$.

"Surubabel, antiga morada" (figura 5) permanecia no entendimento tuxá como território dos antigos, sendo tuxá por extensão, ainda que àquela altura não houvesse uma reivindicação demarcatória explícita por parte do povo, ao menos não como ocorre atualmente com o processo de autodemarcação.

O trabalho recente de Dinamam Jesus Vieira (2017), já referido, também menciona a confecção coletiva dessa cartografia social. $\mathrm{O}$ autor assim apresenta sua percepção sobre a oficina:

Em 2010, construímos pela primeira vez a nova Cartografia Social do Povo Tuxá de Rodelas, trazendo elementos de toda a área tradicional, as ilhas e as cachoeiras sagradas. Nessa circunstância também começa a discussão, a compreensão e o reconhecimento por parte da comunidade, em parceria com a Universidade do Estado da Bahia e Universidade do Estado do Amazonas, da área decretada em 21 de dezembro de 2009 [...] (JESUS VIEIRA, 2017, p. 28).

A todas essas instâncias cartográficas, se assim pudermos chamá-las, somam-se dois símbolos de grande carga semiótica e profundo significado simbólico para os Tuxá: a "destruição pela CHESF" e a "barragem de Itaparica". Aqui, pelo caráter semiótico da composição - e por nossa vivência em campo junto ao povo, quer na aldeia de Rodelas, quer na autodemarcação de Dzorobabé - procederemos a uma consideração hermenêutica do que surge atrelado às legendas acima.

Sob o item "conflito", ambas as imagens traduzem um imaginário de destruição e mesmo irreversibilidade, sobretudo ao colocarmos a cosmologia 
tuxá - donde partem as escolhas imagéticas - como um complexo indígena xamânico que, não obstante, porta em si elementos de um catolicismo profundamente popular. A "destruição pela CHESF", semioticamente representada pela cabeça de um demônio, reforça certa sensação de impotência frente às burocracias estatais e aos estratagemas administrativos, como já pudemos evidenciar.

É também um demônio, a figura do diabo, que despontará entre os grupos estudados por Michael Taussig quando daquilo que o antropólogo identificou como sendo um avanço produtivo do capitalismo (TAUSSIG, 2010). Diz o autor: "agricultores e camponeses - à medida que se tornam trabalhadores assalariados sem-terra - invocam o diabo como parte do processo de manutenção e aumento da produção" (TAUSSIG, 2010, p. 37). Não haveria, aí, dinâmica semelhante à que observamos entre os Tuxá, vítimas do "desenvolvimento capitalista" (SAMPAIO-SILVA, 1997, p. 176) e de suas subsequentes - ou simultâneas - "violações de direitos" (JESUS VIEIRA, 2017)?

Outro episódio evidencia as conexões de uma cosmologia tuxá, indígena e com elementos de um catolicismo popular, com os acionamentos de memórias do desterro pós-barragem a partir de determinados atores indígenas, cujas práticas de representação mostram-se francamente intersemióticas. Em 2017, nos primeiros meses da autodemarcação de Dzorobabé, uma grande liderança tuxá cantaria, para se referir ao ocorrido quando da época da inundação, um sintomático toante de toré, linha musical que acompanha performances e trabalhos dos Tuxá em suas práticas rituais e religiosas. Transcrevemos alguns dos versos, seguidos imediatamente da interpretação advinda da própria cantora, Dora Jurum Tuxá, e que foram captados em um curto documentário produzido à época. Em suas palavras veremos não apenas a dimensão demoníaca do empreendimento que inundou as terras que Dora conheceu quando jovem, mas também seu caráter pecaminoso:

"Trabalha, meu irmão, com fé em Deus

Trabalha, meu irmão, com fé em Deus

Nós trupica, mas não cai

$\mathrm{Ai}$, que povo mau!

Ai, que povo mau!

Pecador da terra, meu irmão

Só paga o bem é com o mal.

[Parando de cantar, Dora se dirige à câmera] Sabe qual é o pecador? É a CHESF! O pecador é a CHESF!"' (SABEH, 2017, 5m08s).

Pecado e destruição, ou a destruição como pecado, surgem conectados nos discursos e nas formas expressivas que os Tuxá mobilizam para compreender a situação histórica na qual se acham enredados. O demônio da “destruição pela CHESF", nas palavras e expressões gráficas dos próprios Tuxá, não apenas abala a realidade no ponto geográfico da barragem de Itaparica, mas também surge entre a Ilha da Viúva, ainda existente no imaginário e na imagem cartográfica, e a margem baiana do rio (figura 5). Há dois pontos topográficos destruídos pelo demônio, e não seria despropositado considerar a destruição como abrangendo toda a área cartografada, tendo em seus pontos iconográficos apenas sínteses do abalo a um modo de vida considerado pleno. Sínteses de um pecado, portanto. Ademais, o demônio da destruição possui, sobre sua cabeça, um balão de pensamento como nas histórias em quadrinhos, e dentro de tal balão aparece, como corolário, a representação gráfica do desenvolvimento capitalista e do progresso: dinheiro, lucro. 


\section{Conflitos}

\section{Destruição pela CHESF \\ Barragem de Itaparica}

Fonte: SANTOS et al., 2008, p. 6-7.

Outro elemento cuja localização extrapola sua coordenada precisa no mapa, pela inclusão das áreas inundadas no perímetro vermelho, a barragem de Itaparica talvez elabore o que o demônio da CHESF sintetiza. Como se observa, a barragem figura como um monstro aquático que devora uma terra produtiva, destruindo as árvores frutíferas que existem sobre as águas - numa clara alusão à inundação da Ilha da Viúva.

Se o demônio/diabo representa o aceleramento da produção e o impacto do desenvolvimento capitalista, a barragem/monstro devorador talvez module sua característica de aparente irreversibilidade. Emergindo das águas - e fazendo-as se elevarem, como a barragem fez acontecer - e destruindo a terra até então conhecida e laborada pelos Tuxá, o monstro parece expressar o pavor que a memória do povo guarda com relação à CHESF. Gilbert Durand talvez identificasse essa carga simbólica da água destruidora com "a figura do irrevogável" (DURAND, 2001, p. 96), e aqui não podemos deixar de notar semelhanças com um arquétipo "ao mesmo tempo teriomórfico e aquático, que é o Dragão". (DURAND, 2001, p. 97).

O autor de "As estruturas antropológicas do imaginário" assim descreveria o dragão, que a iconografia tuxá na Nova Cartografia Social, de algum modo, vem corroborar: "O Dragão parece resumir simbolicamente [...] o monstro antediluviano, animal do trovão, furor da água, semeador da morte [...] uma “criação do medo"”. (DURAND, 2001, p. 97).

Temos, então, para além de uma sobreposição cronológica de espaços vividos pelo povo de Rodelas, alguns simbolismos de densidade semiótica incontestável. É por meio de tais expressões iconográficas que a Nova Cartografia Social dos Tuxá é também cartografia social de uma memória comunitária, coletivamente elaborada - lembremos de seu caráter de oficina conjunta - e etnicamente reveladora - como o toante entoado por Dora e sua própria explanação deixam entrever. É através dessa densidade cartográfica, diríamos, que um complexo imaginário e imagético encontra vazão e constitui matéria de força política explícita, seja pela natureza do projeto cartográfico social, seja por sua publicação material e digital em fascículo.

A sobreposição de espaços caminhados, entretanto, não ocorre apenas no plano estritamente cartográfico, como até aqui elaboramos. Para além de mapas de sensoriamento remoto ou de cartografia social, tivemos oportunidade de observar etnograficamente algo dessa expressividade imagética da memória, através de uma prática diversas vezes constatada junto ao pajé tuxá Armando Apako. Passemos, portanto, a algumas narrativas fluviais dos anciãos tuxá. 


\title{
AMBIENTE E MEMÓRIA TOPOGRÁFICA
}

"Deixem-me começar elucidando", diz Tim Ingold sobre a percepção do ambiente, "o que não é paisagem. Ela não é 'terra', não é 'natureza' e não é "espaço"” (INGOLD, 2002, p. 190, grifo do autor, tradução nossa). Com isso, o antropólogo indica sua predileção pela noção de ambiente, paisagem, como um "plenum", certa totalidade que "não possui lacunas a serem ainda preenchidas, de modo que todo novo elemento é, na verdade, uma reelaboração". (INGOLD, 2002, p. 191, tradução nossa).

Para o autor, a paisagem tampouco será "natureza", posto não se identificar apenas com algum "mundo externo", mas também com o mundo em que, precisamente, os seres habitam - que poderia ser denominado, filosoficamente, de mundo interno, subjetivo ou simbolicamente significado. Por fim, paisagem não é "espaço" por sua clara dimensão de territorialidade vivida - e já retornaremos à territorialidade - que Ingold assim explicita:

\begin{abstract}
"podemos comparar o projeto diário de habitar o mundo com aquele projeto mais peculiar e especializado do agrimensor ou do cartógrafo, cujo objetivo é representar [a paisagem/o mundo]. Ninguém duvida que $\mathrm{o}$ agrimensor, conforme perambula para realizar suas tarefas, experiencie a paisagem mais ou menos como o fazem todos cujos trabalhos e vidas ali residem. Como as outras pessoas, o agrimensor é móvel, ainda que incapaz de estar em mais de um lugar ao mesmo tempo. $\mathrm{Na}$ paisagem, a distância entre dois pontos, A e B, é experimentada como uma jornada percorrida, um movimento corporal de um lugar a outro, com a vista mudando gradualmente ao longo da rota. $\mathrm{O}$ trabalho do agrimensor, entretanto, é realizar medidas instrumentais de um número considerável de localidades, combinando os dados para produzir uma imagem única que é independente de qualquer ponto de observação. Tal imagem é a de um mundo cuja apreensão direta somente seria possível por uma consciência capaz de estar em todos os lugares ao mesmo tempo, e em nenhum lugar particular" (INGOLD, 2002, p. 191, grifos do autor, tradução nossa).
\end{abstract}

O trabalho técnico, agrimensor ou cartográfico, portanto, estaria muito próximo de uma visão aérea, espacial, semelhante ao olhar de uma ave em voo (INGOLD, 2002, p. 191). A este faltaria, num primeiro momento, a materialidade da terra - não da "terra" apenas, mas da terra em seu sentido de vivência plena e multielemental - e, sem dúvida, o movimento pela terra: a caminhada, a mudança de perspectiva, as demais sensações para além do olhar abstrato e categórico.

Guardadas as características artísticas e tecnológicas entre os mapas de Halfeld e Santos Vieira, dois engenheiros de séculos diferentes, podemos ver o mesmo recurso sendo utilizado: mapas com visão aérea, disposições cartográficas mais ou menos fiéis às medições de terreno, às condições ambientais medidas pela ciência. O que Santos Vieira inicialmente nos mostrou, entretanto, foi a possibilidade de sobreposição espaço-temporal em uma carta gráfica, que vimos realizada também na Nova Cartografia Social tuxá. Mas essa sobreposição espaço-temporal, como aventamos, parece dizer respeito muito mais à sobreposição de uma memória étnica sobre técnicas de representação já estabelecidas. Como se as "memórias do desterro" (CRUZ, 2017) viessem reelaborar o mapa técnico cuja base é construída em um satélite; como numa cartografia do imaginário sobre um cartograma já estabelecido.

Há casos, entretanto, em que memórias topográficas são recordadas em um processo cujo objetivo não é a confecção de mapas gráficos. Antes, são conhecimentos topográficos de sujeitos cuja vida foi grandemente vivida nas 
paisagens que descrevem, mesmo décadas após sua drástica mudança. Tomaremos dois breves exemplos de narrativas orais em que se constata essa memória da paisagem cujo aprendizado ocorreu no processo mesmo de caminhada - ou navegação.

No fascículo da Nova Cartografia Social dos Tuxá de Rodelas, lemos um relato do cacique Bidu, um dos anciãos que viveu a Ilha da Viúva e a navegação do São Francisco até mais de cinquenta anos de idade. Ele conta:

\begin{abstract}
Primeiro lá, perto de Paulo Afonso, tinha a [cachoeira] de Itaparica que não passava mais ninguém. Essa aí, quem vinha de lá ficava assim mesmo. Depois tinha a cachoeira de Seo Pedro Dia, cachoeira fortíssima. Fica pertinho da antiga cidade de Barreira. Sobe, vem os Mandante, depois vem Itaquatiara, cachoeiras forte. De Itaquatiara tinha o Baxio do Val, que era um baxio raso de água muito violenta. Aí tinha o Croá que era aqui perto de Rodela, era cachoeira também. Depois do Val, vinha a cachoeira do outro lado, a Cachoeira do Croá. O Croá, quem vinha de lá não passava, que não tinha passagem. Quem discia, ou discia inteiro ou discia aos pedaços, mas tinha que descer. Aí vem aqui, nós. Aí tem várias cachoeirinhas pequenas. Passava aqui e tinha a cachoeira de Boi Véi. Tinha a cachoeira do Dorado, tamo pra Belém. Tinha a cachoeira perto da Barra de Tarrachil. Croá ficava na Bahia e o [baxio] Val em Pernambuco. Tinha que passar pelo Val, descendo ou subindo, que pelo Croá não passava, ninguém queria passar lá. Mas um doido soltou a canoa, desamarrou a canoa e deitou na canoa pra morrer, destinado a morrer, passou vivinho! Nem a canoa virou, nem quebrou e nem ele morreu. (CACIQUE BIDU, apud SANTOS et al, 2010, p. 3).
\end{abstract}

Como muitos dos homens Tuxá mais velhos, Bidu possui um vasto conhecimento prático sobre a navegação fluvial à época do rio corrente. A memória das ilhas, muitas mais do que apenas a da Viúva, permanece vivíssima nas histórias e narrativas que tantas vezes ouvimos junto a estes índios. No relato acima transcrito, curiosamente notamos certas sobreposições temporais em alguma medida semelhantes às observadas nas cartas gráficas: quando Bidu diz da antiga cachoeira de Seo Pedro Dia, "cachoeira fortíssima", completa dizendo, no presente, que ela "fica pertinho da antiga cidade de Barreira". Fica, não ficava. A sequência também se mantém distante do pretérito: "sobe, vem os Mandante, depois vem Itaquatiara." O cacique prossegue, dizendo que "aí tem várias cachoeirinhas pequenas", muito embora a barragem em 1988 tenha acabado com todas.

Esse conhecimento supratemporal do território, porque vivido no passado e rememorado no presente, faz-nos recordar da noção geográfica e antropológica de territorialidade. Como a paisagem de Ingold, territorialidade não se restringe a concepções e relações técnicas e utilitárias com o território, mas abrange uma vasta rede de correlações, afetos e constituições de subjetividades entre aqueles humanos - e não-humanos - que pelo território vivem e caminham. Territorialidade como "historicidade da cultura, da experiência historicamente vivida" (VIEIRA; AMOROSO; VIEGAS; 2015, p. 12) por um povo ou por sujeitos individuais de um grupo humano.

Mas além da narrativa oral transcrita acima, com a topografia fluvial vivamente descrita pelo cacique Bidu, um episódio sempre me chama a atenção quando estou junto aos Tuxá. Este é o causo do batim narrado pelo pajé Armando Apako, também ancião e exímio conhecedor das águas antigas do São Francisco.

Assim como a topografia, assim como a paisagem, determinadas histórias são pontos de referência reconhecíveis para aqueles que por ali transitam. 
A história do batim e da capivara, que parafrasearemos, é um desses pontos: os Tuxá que convivem mais cotidianamente com o pajé Armando, isto é, sua família e agregados, decerto já ouviram tal história inúmeras vezes, de modo a poder replicá-la ou incitá-lo a contá-la. A narrativa se passa - e nos leva para quando o rio corria por cachoeiras e ilhas, e os homens saíam em suas canoas para caçar nas ilhotas e nas margens repletas de vegetação e fauna.

Seu Armando então estabelece o cenário e os instrumentos narrativos precisos para a contação: nas águas correntes, navegando em sua canoa, viu ao longe uma série de outras canoas circundando uma ilhota, um amontoado de terra e galhos. Consigo, trazia o batim, pequeno arpão acoplado à ponta de uma flecha, com o qual dizia não errar jamais. Aproximou-se da reunião de embarcações e viu que montavam guarda naquele local. Quando questionados, os outros índios disseram ter visto algo grande se escondendo em meio à vegetação, dentro d'água, e julgavam ser talvez um peixe enorme. Entretanto, ninguém ali arriscava atirar no ponto onde viram o animal, por medo de perderem suas flechas entre água e plantas.

O pajé firmou a vista, com sua canoa fechando o cerco junto aos companheiros, e esquadrinhou a ilhota. Bem distante, em meio a galhos retorcidos, divisou o que sempre diz terem sido "dois buracos". Dois buracos, afinal, que correspondiam às ventas do animal escondido. Declarou aos companheiros que atiraria com seu batim, e que só haveria dois resultados possíveis: acertando no buraco, teria alcançado o objetivo; do contrário, erraria, provavelmente perdendo o batim.

Seu Armando costuma contar essa história numa sequência em que também narra a ocasião em que seu batim foi perdido. Mas isso não ocorreu naquela situação: ao atirar no buraco, pôde acertar em cheio na narina do que descobririam ser uma capivara imensa, que "parecia a mãe das capivaras", conforme conta.

Antes de analisarmos o que aqui quero chamar de memória topográfica, recordemos o cenário sensorial - e ambiental - vivido pela experiência caçadora. Os índios, em suas canoas, balançavam sobre as águas correntes do rio São Francisco muito antes do represamento. As margens, ilhas e ilhotas repletas de fauna e flora davam àquele trecho do curso d'água uma vitalidade dificilmente vista hoje, devido ao impacto da barragem. A própria composição do evento, com índios portando arcos e batins para a caça, é virtualmente impossível na atualidade.

O pajé, ao rememorar essa ocasião, costuma narrá-la de acordo com um recorte topográfico quase invariável. Fala do rio, das ilhas e ilhotas, das outras canoas cercando o animal encurralado e assim por diante. Em dada oportunidade, estando na autodemarcação de Dzorobabé, pude capturar uma imagem que apela para o caráter intersemiótico da história do pajé, e que enfatiza o caráter cartográfico dessa memória topográfica: 
Figura 7 - Pajé tuxá Armando Apako cartografando a história do batim e da capivara

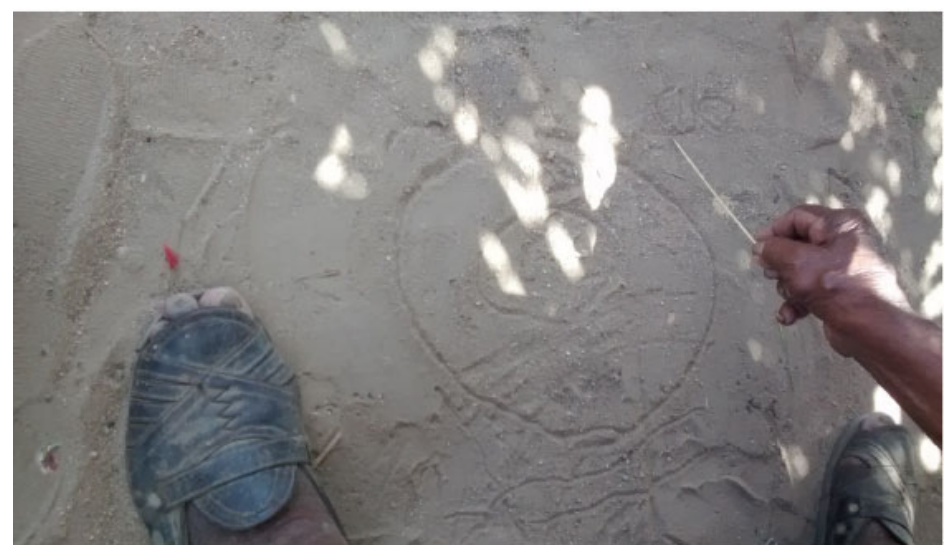

Fonte: Leandro Durazzo.

Nela, vemos o pajé desenhando no chão enquanto conta o ocorrido, e observamos um detalhe de sobreposição iconográfica bastante similar às legendas da Nova Cartografia Social, qual seja, a representação gráfica dos "dois buracos" da capivara sobre um plano cartográfico inicialmente aéreo. Observa-se, no centro da imagem, o início da narrativa: uma ilhota circundada (por canoas), e sob a imagem os dois traços que indicam o rio corrente. No canto superior direito, capturando o movimento daquele instante, o pajé acabara de acrescer o animal que parecia "a mãe das capivaras", em sua forma ainda misteriosa e submersa. Antes de ser caçada, portanto, e antes de figurar como alimento conquistado.

A memória topográfica do pajé e a Nova Cartografia Social dos Tuxá ainda oferecem elementos para pensar. De um lado, temos o animal terrestre e aquático, submerso e misterioso, que o pajé virá caçar. Do outro, o monstro teriomórfico e aquático que destrói a Ilha da Viúva, a abundância produtiva das árvores e da terra cultivada, cujo avanço se mostrou inexorável feito a marcha do progresso. Em ambos os casos, entretanto, temos as reconfigurações de um entendimento indígena sobre a paisagem e a territorialidade vivida. Um potencial cartográfico intenso, portanto, sobretudo se considerarmos que

Cartografia [...] não deve ser tomada apenas no sentido convencional do termo, como um conjunto de mapas que definem um território, mas como uma composição calidoscópica de textos, em diversos gêneros e modalidades, com diversas intenções discursivas, para desenhar e refletir sobre um determinado campo de ação ou 'território', seja ele material ou simbólico. Essa composição de diversos textos, que podem ser montados e desmontados por diversos ângulos de análise, gerando outros textos, se faz demarcada pelas contingências institucionais de pesquisa, da própria linguagem como fenômeno/discurso e dos sujeitos da pesquisa, sejam eles 'pesquisadores' ou 'pesquisados. (CÉSAR; COSTA; 2013, p. 33).

Como o caso tuxá nos mostra, é possível pensar em maneiras diversificadas de representar o território vivido, para fins também diversos que vão desde o estudo técnico sobre impactos até os impactos no plano simbólico que determinado grupo opta por iconizar. O que aprendemos a partir da observação dessa variada lida com as imagens topográficas, e com as cartografias sociais de memórias e imaginário, é que nenhum recurso permanece inalterado: mapas objetivos e exploratórios, visões de pássaros em voo, transformam-se em rica iconografia simbólica de um povo instado a lidar com um monstro não-indígena, a compreender e reelaborar sua relação com impactos gerados por uma lógica de 
desenvolvimento econômico estatal e também interétnico que, historicamente, pouca atenção concede aos indígenas.

Não obstante, tais memórias e representações gráficas também possibilitam agências variadas no contexto de uma pós-destruição. Há o conhecimento de uma paisagem que se desfez pela ação do "demônio", mas também há conhecimentos passíveis de reprodução e implementação em novos contextos, como observamos com o recrudescimento da pesca artesanal por ocasião da autodemarcação de Dzorobabé.

Simultaneamente à contação de histórias do pajé, sentado junto ao fogo em terra firme, alguns Tuxá poderiam estar - e muitas vezes estavam mergulhados no rio ou por ele navegando, de arpão, vara ou rede em mãos, para tirar das águas calmas uma nova corrente de subsistência. Novas vidas sobrepostas à memória da antiga, portanto, e projetadas para um futuro em que a demarcação territorial finalmente seja assegurada.

\section{NOTAS}

${ }^{1} \mathrm{O}$ presente trabalho foi realizado com apoio da Coordenação de Aperfeiçoamento de Pessoal de Nível Superior - Brasil (CAPES) - Código de Financiamento 001.

${ }^{2}$ Este artigo utiliza iniciais maiúsculas quando em referência a etnônimos e indivíduos (povo Tuxá, o Tuxá...), e minúsculas quando o etnônimo se apresenta na forma adjetival (o engenheiro tuxá, os pesquisadores tuxá). Ademais, não flexionamos o adjetivo etnonímico em plural, cf. Convenção para grafia dos nomes tribais da Associação Brasileira de Antropologia (ABA, 1954, p. 150-152) e Manual de Redação da Fundação Nacional do Índio (FUNAI, 2016, p. 18ss). O mesmo não ocorre com o nome de seus antepassados, os índios rodeleiros, que tratamos neste texto como adjetivo qualificador das populações sanfranciscanas das quais descendem os Tuxá, e não como etnônimo reivindicado enquanto tal. Neste caso, grafaríamos Rodeleiros, com inicial maiúscula, mas ainda assim com flexão de número (e não Rodeleiro) pela natureza vernácula do nome historicamente atribuído a tais grupos. Sobre a variedade de etnônimos e atribuições nominais na região do sertão do São Francisco no período colonial, ver o trabalho de Cristina Pompa (2003, p. 295ss).

3 "As terras em disputa, que totalizam mais de 4,3 mil hectares, também haviam sido destinadas para reassentamento dos agricultores [da antiga Rodelas] em razão da obra [de construção da hidrelétrica]. Em abril de 2015, o ministro deferiu liminar para suspender o decreto. Em junho de 2018, por entender que ações sobre o tema são consequência da falta de prévio diálogo em busca de uma solução consensual, o ministro indagou as partes [indígenas e agricultores não-indígenas] acerca do interesse em buscar uma conciliação. Com a resposta favorável, determinou o encaminhamento dos autos ao CCAF [Câmara de Conciliação e Arbitragem da Administração Federal]" (STF, $2018, \mathrm{~s} / \mathrm{p}$ ). Com isso, revogou-se a suspensão do processo, embora não tenha havido até a data de revisão deste artigo, novembro de 2018, maiores desdobramentos do caso.

${ }^{4}$ Segundo o site oficial do projeto, este "tem como objetivo dar ensejo à auto-cartografia dos povos e comunidades tradicionais na Amazônia [onde o projeto se inicia, estendendo-se depois a outras regiões do país]. Com o material produzido, tem-se não apenas um maior conhecimento sobre o processo de ocupação dessa região, mas sobretudo uma maior ênfase e um novo instrumento para o fortalecimento dos movimentos sociais que nela existem. Tais movimentos sociais consistem em manifestações de identidades coletivas, referidas a situações sociais peculiares e territorializadas. Estas territorialidades específicas, construídas socialmente pelos diversos agentes sociais, é que suportam as identidades coletivas objetivadas em movimentos sociais. A força deste processo de territorialização diferenciada constitui o objeto deste projeto. A cartografia se mostra como um elemento de combate. A sua produção é um dos momentos possíveis para a autoafirmação social. É nesse sentido que o PNCSA busca materializar a manifestação da autocartografia dos povos e comunidades nos fascículos que publica, que não só pretendem fortalecer os movimentos, mas o fazem mediante a transparência de suas expressões culturais diversas" (PNCSA, s/d, s/p). 


\section{REFERÊNCIAS}

ABA, Associação Brasileira de Antropologia. Convenção para grafia dos nomes tribais. Revista Brasileira de Antropologia, v. 2, n. 2, 1954, p. 150-152.

CABRAL NASSER, Elizabeth Mafra. Sociedade Tuxá. Dissertação (Mestrado em Ciências Humanas). Programa de Pós-Graduação em Ciências Humanas. Salvador: UFBA, 1975.

CÉSAR, América Lúcia Silva; COSTA, Suzane Lima. Cartografia da educação indígena: relato de uma experiência de pesquisa intercultural e interétnica. In: ;___ (Org.). Pesquisa e escola: experiências em educação indígena na Bahia. Salvador: Quarteto, 2013.

CRUZ, Felipe Sotto Maior. Quando a terra sair: os índios Tuxá de Rodelas e a barragem de Itaparica: memórias do desterro, memórias da resistência. Dissertação (Mestrado em Antropologia Social). Programa de Pós-Graduação em Antropologia Social. Brasília: UnB, 2017.

DURAND, Gilbert. As estruturas antropológicas do imaginário: introdução à arquetipologia geral. Tradução de Helder Godinho. 2. ed. São Paulo: Martins Fontes, 2001.

FUNAI, Fundação Nacional do Índio. Manual de Redação Oficial. Brasília: FUNAI, 2016.

GALINDO, Marcos. O Governo das Almas: A expansão colonial no país dos Tapuia 1651-1798. Tese de Doutorado. Leide: Leiden Universiteit, 2004.

GRÜNEWALD, Rodrigo de Azeredo. Toré: regime encantado do índio do Nordeste. Recife: Fundaj, Editora Massangana, 2005.

HALFELD, Henrique Guilherme Fernando. Atlas e relatório concernente a exploração do Rio de S. Francisco desde a Cachoeira da Pirapora até ao Oceano Atlântico: levantado por Ordem do Governo de S. M. I. O Senhor Dom Pedro II. Rio de Janeiro: Lithographia Imperial, 1860. Disponível em <www2. senado.gov.br/bdsf/item/id/185636 >. Acesso em: 31 mar. 2018.

INGOLD, Tim. The perception of the environment: essays on livelihood, dwelling and skill. London/New York: Routledge, 2002.

JESUS VIEIRA, Antônio Fernandes de. Os indios Tuxá na rota do desenvolvimento: violações de direitos. Dissertação (Mestrado em Desenvolvimento Sustentável). Programa de Pós-Graduação em Desenvolvimento Sustentável. Brasília: UnB, 2017.

NASSER, Nássaro A. S. Economia Tuxá. Dissertação (Mestrado em Ciências Humanas). Programa de Pós-Graduação em Ciências Humanas. Salvador: UFBA, 1975.

NIMUENDAJU, Kurt. Mapa etno-histórico do Brasil e regiões adjacentes. 2 ed. Brasília, DF: IPHAN, IBGE, 2017. Disponível em: <http://portal.iphan.gov. br/indl/pagina/detalhes/1563>. Acesso em: 31 mar. 2018.

PACHECO DE OLIVEIRA, João. Uma etnologia dos "índios misturados"? Situação colonial, territorialização e fluxos culturais. Mana, Rio de Janeiro, v. 4, n. 1, p. 47-77, Abril 1998. Disponível em: <http://www.scielo.br/scielo. php?script=sci_arttext\&pid=S0104-93131998000100003\&lng=en\&nrm=iso $>$. Acesso em: 31 mar. 2018.

PNCSA, Projeto Nova Cartografia Social da Amazônia. Apresentação. s/d. Disponível em: <http://novacartografiasocial.com.br/apresentacao/>. Acesso em: 25 nov. 2018.

POMPA, Cristina. Religião como tradução: missionários, Tupi e Tapuia no Brasil colonial. Bauru: Edusc, 2003. 
SABEH, Sociedade Brasileira de Ecologia Humana. Dzorobabé Autodemarcação Tuxá. 2017. 9m38s. Disponível em: <https://youtu.be/Z8aAE2Kkfnw>. Acesso em: 26 nov. 2018.

SALOMÃO, Ricardo D. B. Etnicidade, territorialidade e ritual entre os Tuxá de Rodelas. Dissertação (Mestrado em Antropologia Social). Programa de Pós-Graduação em Antropologia Social. Niterói: UFF, 2006.

SAMPAIO-SILVA, Orlando. Tuxá: índios do Nordeste. São Paulo: Annablume, 1997.

SANTOS, Juracy Marques dos. Cultura material e etnicidade dos povos indígenas do São Francisco afetados por barragens: um estudo de caso dos Tuxá de Rodelas, Bahia, Brasil. Tese (Doutorado em Cultura e Sociedade). Programa Multidisciplinar de Pós-Graduação em Cultura e Sociedade. Salvador: UFBA, 2008.

et al. Cartografia Social dos Povos e Comunidades Tradicionais do $\overline{B r a s i l}$ : Tuxá de Rodelas. Manaus, AM: Projeto Nova Cartografia Social da Amazônia / UEA Edições, 2010.

SANTOS VIEIRA, Élton Fábio. Povo Tuxá Aldeia Mãe: impactos geoambientais e culturais decorrente da implementação da barragem de Itaparica. Monografia (Bacharelado em Engenharia Civil). Feira de Santana: UEFS, 2016.

; SANTOS, Rosangela Leal; CARELLI; Liamara. Identificação de território indígena: uma reconstituição histórica e geopolítica do povo Tuxá (Rodelas-BA). In: Anais do XVII Simpósio Brasileiro de Sensoriamento Remoto - SBSR. João Pessoa: INPE, 2015, p. 7133-7140.

STF, Supremo Tribunal Federal. Relator envia processo sobre conflito de terras na Bahia à Câmara de Conciliação e Arbitragem da Administração Federal. Noticias STF. Disponível em: <http://stf.jus.br/portal/cms/verNoticiaDetalhe. asp?idConteudo=395135> . Acesso em: 26 nov. 2018.

TAUSSIG, Michael T. O diabo e o fetichismo da mercadoria na América do Sul. Tradução de Priscila Santos da Costa. São Paulo: Ed. UNESP, 2010.

VIEIRA, José Glebson; AMOROSO, Marta; VIEGAS, Susana de Matos. Apresentação: Dossiê Transformações das Territorialidades Ameríndias nas Terras Baixas (Brasil). Revista de Antropologia/USP, vol. 58, n. 1, 2015, p. 9-29. 